\title{
Management of Internal Mammary Artery Spasm
}

\author{
Edam Ziadinov ${ }^{*}$, Nasser Al-Kemyani ${ }^{2}$, Hilal Al-Sabti1 \\ ${ }^{1}$ Department of Surgery, Cardiothoracic Surgery Division, Sultan Qaboos University Hospital, Muscat, Oman \\ ${ }^{2}$ Department of Anesthesia and Intensive Care, Sultan Qaboos University Hospital, Muscat, Oman \\ Email: $\underline{\text { edam1984@mail.ru }}$
}

Received 4 February 2014; revised 2 March 2014; accepted 21 March 2014

Copyright (C) 2014 by authors and Scientific Research Publishing Inc.

This work is licensed under the Creative Commons Attribution International License (CC BY).

http://creativecommons.org/licenses/by/4.0/

c) (i) Open Access

\begin{abstract}
The article is dedicated to the management of internal mammary artery spasm intra- and postoperatively based on the accumulated evidence in the literature. It provides a stepwise decision algorithm for safely resolving the spasm and prevention of relapse.
\end{abstract}

\section{Keywords}

Internal Mammary Artery Spasm; Coronary Artery Bypass Grafting; Vasodilation

\section{Introduction}

The left internal mammary artery (IMA) is the most widely used graft and is predominantly anastomosed to the left anterior descending artery (LAD), which is considered as a gold standard in coronary artery bypass surgery (CABG) [1].

Vasoreacivity is a complex process, which presents in homeostatic equilibrium between constriction and dilation, and it is induced by a number of different neurotransmitters, cascades and receptors. IMA owns histo-anatomical features of a somatic artery and is capable of undergoing severe spasm. It has been described in literature case reports that intractable spasm of IMA leads to transmural myocardial infarction and death [2] [3]. The real incidence of this dangerous complication is unknown due to several reasons. One of them is the absence of an immediate angiographic study in each case where ischemic episode occurred. Second, when a patient develops postoperative myocardial ischemia, usually he gets treating empirically with nitroglycerin and tapers down noradrenaline, which may relieve the spasm. Third, if it is ultimately decided to take the patient to the cathlab, and by the time the patient reaches there, the spasm may spontaneously resolve which results in normal angiography.

The first report about IMA vasospasm was by Sarabu M. et al. in 1987 in which the authors described two

"Corresponding author. 
cases of postoperative spasm successfully managed by intragraft application of vasodilators [4]. One year later, Kong et al. described the angiographic presentation of IMA spasm in a patient who underwent CABG [5].

In order to prevent IMA spasm, different pharmacological agents have been used in the last 50 years. The most famous one is the solution of papaverine [6] [7], which initially was proposed to be injected intraluminally. However, due to the fact that it adversely affects the endothelium because of acidity, presently it is applied topically only. Despite many other drugs available for spasm prevention, papaverine remains in use in the majority of cardiac centers.

Looking through the publications in recent years regarding the use of different vasodilators to prevent IMA spasm, we found that the results of many studies have controversial evidence. We would not mention all of them, but we will be summarizing some of the drugs used in daily practice such as nitroglycerin, calcium antagonists and sodium nitroprusside which have been firmly proven to be effective. The use of topical vasodilators also gained a lot of interest among investigators. A group of investigators from Turkey compared different vasodilators for topical use, and found that they cause approximately the same level of IMA vasodilation [8]. However, other investigators showed absence of dilatory effect of topical vasodilators [9]-[11]. This questions the need to prevent spasm when blood flow is adequate. It is important to remember that forceful vasodilation may lead to reciprocal increase in production and storage of endogenous constrictors in order to maintain homeostasis, which may cause vasospasm afterwards.

This article provides insight to the treatment of IMA spasm, not the prevention. Based on the available literature, we created an algorithm to manage IMA spasm intra- and postoperatively.

\section{Management of IMA Spasm}

IMA spasm is a challenging condition. Its management starts from establishing the baseline condition of the patient. Comorbidities such as hypertension, diabetes, and dyslipidemia have significant impact in developing endothelium dysfunction and increased sensitivity for endogenous vasoconstrictors [12]-[14]. In vitro experiments demonstrated that hypertension reduces the response to passive stretching of the IMA, increases basal tone, and impairs nitric oxide release [15].

Revision of preoperative medication chart may reveal a drug causing IMA vasoconstriction. Knowing the mechanism of its action, one can identify a potential antagonist to relieve the spasm. Here is a list of pharmacological groups with proven vasospastic effect on the IMA: alpha-adrenoreceptor agonists, beta-blockers, acetylcholine antagonists, calcium, triptans, glibenclamide and noradrenaline.

It is also important to look for and treat any metabolic or electrolyte imbalances such as hypokalemia [16], hypercalcemia [17], hypomagnesemia, and hypoglycemia, which may contribute to the IMA spasm. An increase of serum lactate suggests a general vasospastic condition; and the presence of simultaneous vasospasm in several grafts and coronary arteries suggests a metabolic disorder rather than a local imbalance. The presence of left main coronary artery stenosis is an extremely unfavorable factor calling for immediate actions [3]. If hypokalemia is present, it has been reported that the use of diltiazem [18] and levosimendan [19] fast resolve IMA spasm due to the opening of potassium channels in the artery.

\section{Intraoperative Management}

Intraoperatively, IMA spasm presents as reduced or absent blood flow in the graft. That is why it is recommended to dissect the artery right after harvesting to assure flow adequacy; otherwise it will be a waste of time to manage the spasm when the patient is already on cardiopulmonary bypass. Generally, it is not a dangerous condition, though may limit the use of IMA.

Here is a stepwise algorithm for the management of intraoperative IMA spasm (Figure 1):

1) Along with the above mentioned revision of comorbidities, preoperative medications and verification of current metabolic status, it is recommended to cannulate the IMA and inject a warm solution of a vasodilatorsodium nitroprusside (SNP) alone [20] or "combination solution" of calcium channel blocker (verapamil, dihydropyridine) [21] and organic nitrate (nitroglycerin) [22]. It is important to maintain the temperature of administered fluids at 37C, since it has been shown that application of normothermic (37C) saline solution is as effective as topical papaverine at room temperature [23]. We recommend the use of SNP or the "combination solution" because they are highly potent, widely available, and safe. Several authors reported that sodium nitroprusside is 


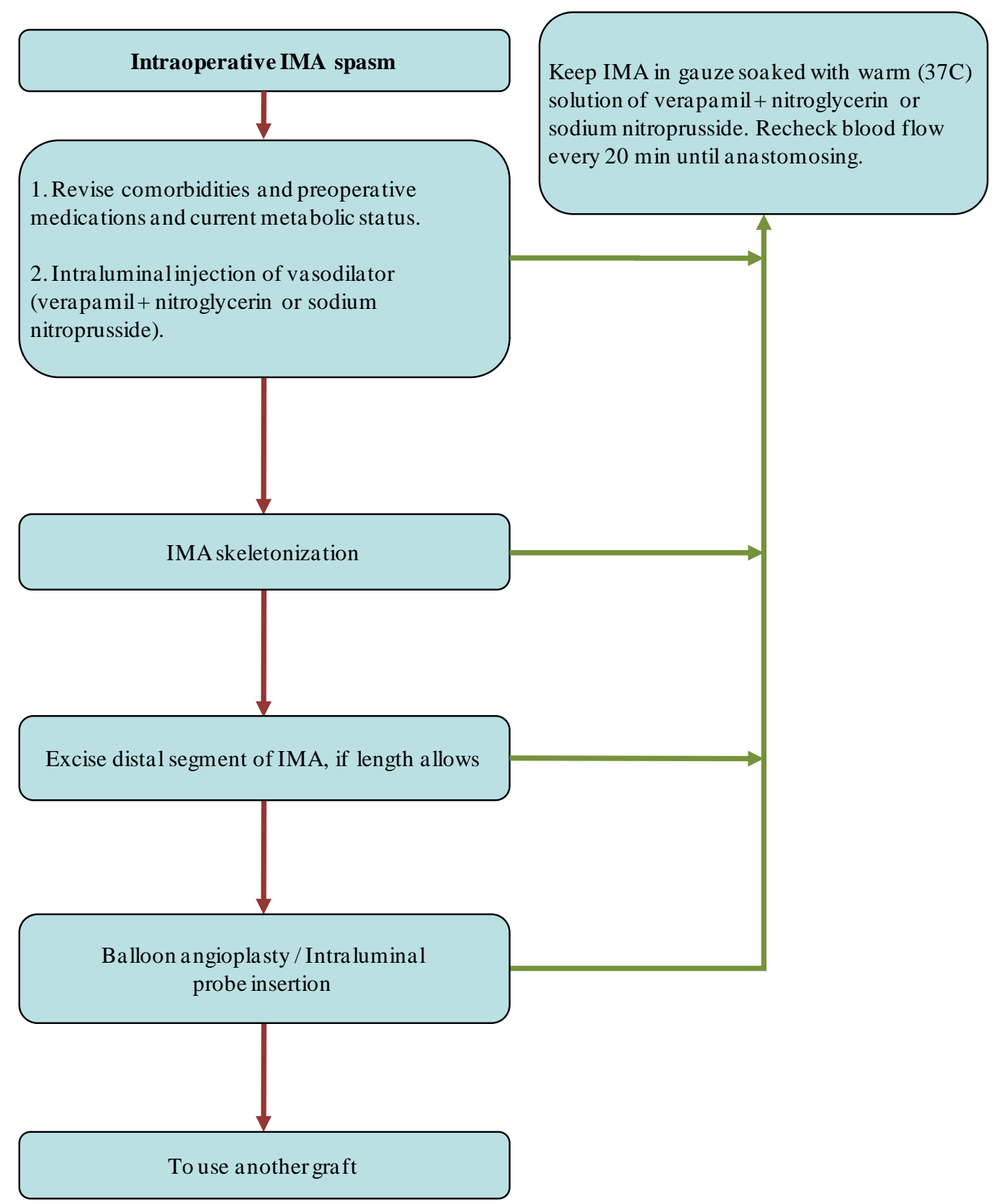

Figure 1. Stepwise algorithm for the management of intraoperative IMA spasm.

more potent than nicardipine, nicorandil, fenoldopam, hydralazine, adenosine, and labetalol [20] [21]. Nevertheless, according to other authors the "combination solution" is as effective as sodium nitroprusside [22]. Intraluminal route is more preferable than topical or in-pedicle injection; and one should remember to check the IMA afterwards for possible dissection. No intraluminal papaverine should be injected as it adversely affects the endothelium because of acidity.

2) Skeletonization of the IMA abolishes sympathetic nervous system influence, dilates the artery and increases blood flow. This was proven by measuring flow before and after skeletonization [24], as well as the absence of sensitivity to noradrenaline in free IMA grafts [25].

3) IMA spasm may be diffused and limited. The distal segment of IMA is usually more involved in spasm as vasoconstrictive receptors are more expressed in a distal direction [12] [26]. If the length of IMA allows, we recommend to shorten it, and to see whether flow improves. If not, then mechanical dilation will be required. 
4) In our literature search, we found three reports about different atraumatic devices for routine dilation of the IMA [27]-[29]. Presently, they are not widely used due to the fact that they may injure the endothelium and thereby reduce the long term graft patency. The coronary angioplasty balloon may theoretically be inflated within the spasm area, though it has never been reported. The coronary steel probe introduction into IMA is a rough procedure and may be used only as a last resort. In our experience, we had two cases of reduced flow, where the probe perforated the IMA mid-segment.

5) If despite all the above measures, the IMA spasm persists, then it is time to consider using another graft.

When the spasm resolves, the IMA should be clamped by bulldog, not clipped. Flow should be refreshed and reassured every $20 \mathrm{~min}$ in order to remove degraded products from stagnated blood. The IMA should be kept in gauze soaked with warm solution of the above mentioned vasodilators.

Ultrasound flow measurement and photo dynamic eye system may be useful tools to recognize spasm developed after the anastomosis is performed, and to treat the spasm accordingly avoiding unnecessary intervention [30]. Bolus administration of calcium chloride should be avoided after separation from CPB as it may significantly reduce flow and triggers vasospasm of the IMA [17].

\section{Postoperative Management}

IMA spasm rarely occurs in the postoperative period, and is characterised by ST-segment elevation in the grafted territory, rising cardiac enzymes, hemodynamic instability, and cardiac arrest. The best diagnostic method of IMA spasm is a coronary angiography where a contrast filling defect during spasm should be distinguished from atherosclerotic plaque [31] and kinking (particularly in a long or twisted vessel).

Spasm of the IMA usually occurs during the first hours postoperatively as a reaction for the surgical intervention. Nevertheless, a case of IMA spasm shown on angiography has been reported in a patient with classical angina four years postoperatively [32].

In the same manner, we created a stepwise algorithm for the management of postoperative IMA spasm: (Figure 2)

1) If coronary angiography shows evidence of IMA spasm, it means that the spasm is sustained and serious, and so prompt actions are required. The first action is injection of warm (37C) solution of SNP or "combination solution" into the IMA [4] [16] [20] [21] [33]. Together with this, it is necessary to revise current medications,

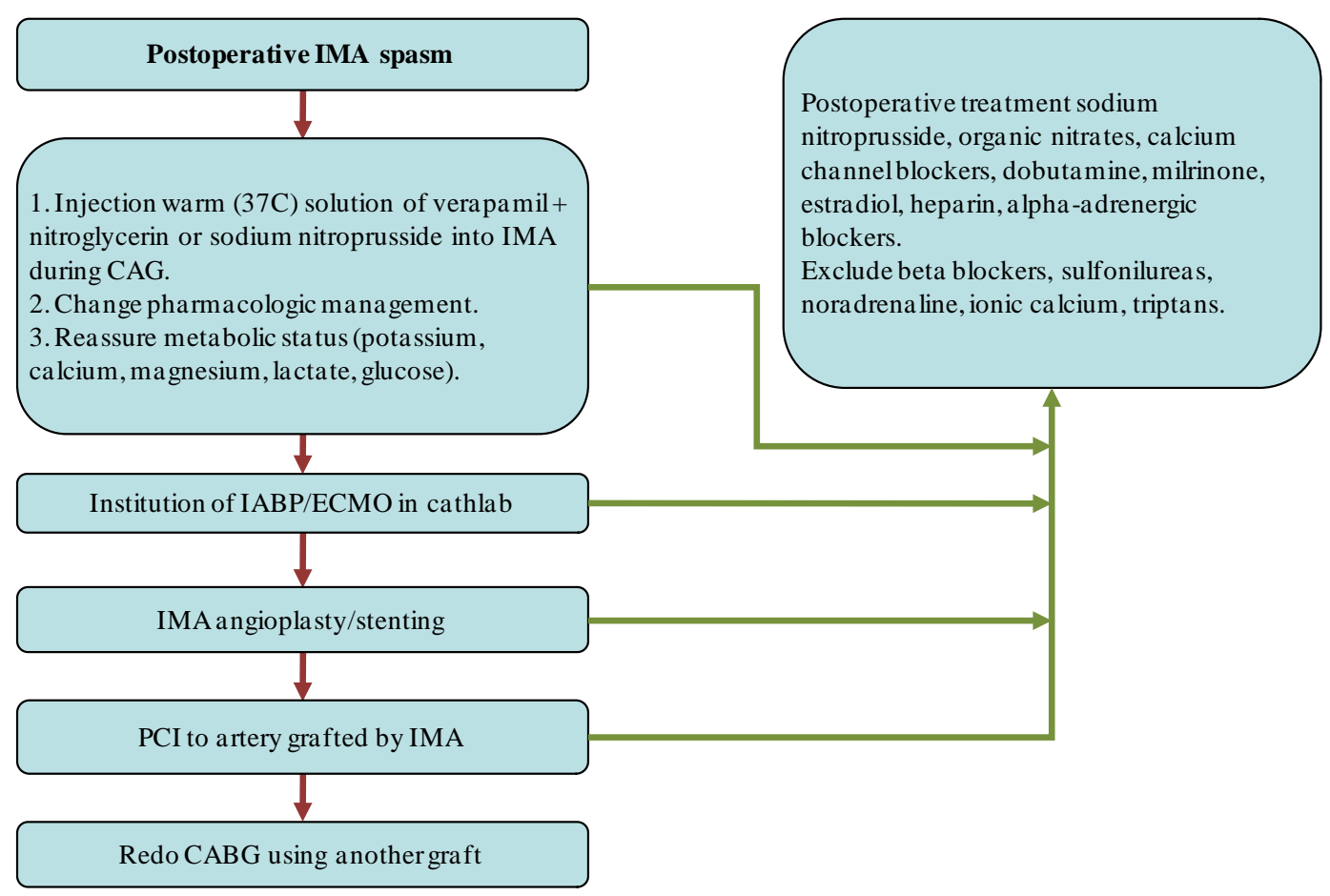

Figure 2. Stepwise algorithm for the management of postoperative IMA spasm. 
inotropes, to check electrolytes, lactate, and glucose with subsequent rectification. These measures exhibited efficacy in a number of reports, though may be insufficient.

2) Next step would be establishing cardiocirculatory support, as it was reported that early institution of extracorporeal membrane oxygenation (ECMO) and controlled cardiocirculatory assistance significantly improves survival, especially in cases where IMA spasm is associated with spasm of other grafts or coronary arteries [3] [34]. IMA spasm itself is matter of several hours and circulatory support is an insurance which helps to overcome short ischemic period [33]. Once patient's hemodynamic stability secured, further interventions can be done.

3) IMA angioplasty/stenting is a peculiar procedure and has been successfully performed in IMA spasm [35], stenosis and anastomotic stricture. Lack of experience for such interventions or diffuse spasm is limitations for the latter.

4) Stenting of the coronary artery (usually LAD) grafted by IMA could be an alternative. This helps to avoid myocardial infarction, though may create competitive flow [36].

5) If despite of all measures, the patient still has signs of ongoing ischemia due to the IMA spasm, it is necessary to change the graft and preferably to do it soon. Vogt et al. described a case with distal IMA spasm. Initially, it got relieved by nitroglycerin intra IMA injection, but because of respasm they did redo bypass using vein graft, which prevented myocardial infarction [37].

After relieving the spasm, it is important to maintain the vessel patency by administering dilators and avoiding constrictors. Here is a list of drugs that cause IMA dilation: sodium nitroprusside [21], organic nitrates [38], calcium channel blockers [4] [52], 17beta-estradiol (evidence only for females) [39], natriuretic peptides [40], low molecular weight heparin [41], alpha-adrenergic blockers (in benign prostate hyperplasia), resveratrol [42], iloprost [43], fasudil [44].

Inotropic drugs are routine in post cardiac surgery treatment and have strong impact on IMA vasoreactivity. Among of all drugs dobutamine appears to be superior to others in terms of IMA dilation [45]. Levosemindan [46]-[48] and milrinone [49]-[51] exhibited moderate dilatory effect through some different biochemical pathways. Adrenaline is influencing on IMA unpredictably, due to stimulation several antagonizing receptors. Noradrenaline in turn is a potent vasoconstrictor and generally should be rejected or reduced.

In diabetic patients, sulfonilureas should be replaced by other hypoglycemic agents, such as thiazolidinediones [52] which displayed soft dilatory properties. Beta blockers may be substituted to ivabradin, or at least to nebivolol or carvedilol with their preferred additional vasodilatory effects.

\section{Discussion}

IMA spasm is a complication that precludes the use of the graft intraoperatively and causes myocardial infarction postoperatively [2] [34]. Many techniques and drugs have been introduced to deal with this complication. Initial studies compared the ability of different pharmacological agents to dilate the IMA assuming spasm as a single self-limited process. Later, it was understood that vasoreactivity is multifactorial process triggered via various metabolic pathways.

There are more than hundred reports in current literature related to pharmacological prevention of IMA spasm. However, until now there is no unified consensus about using the exact mediction, its dosage and route of administration. What is interesting is that some drugs have additional vasoprotective properties which may improve long-term graft patency. Provided the fact that intraoperatively grafts usually pass through a short period of ischemia between harvesting and being anastomosed during which pathological cascades usually occur which adversely affect the endothelium, so adequate vasoprotection is preferable to preserve graft viability. For instance, it is known that early postoperative aspirin intake increase long-term patency and at the same time preoperative aspirin intake is avoided due to the risk of bleeding. Thus, it would be interesting to investigate the long-term patency of the IMA with intraoperative topical application of aspirin. In the same manner, other topical protector-dilators such as natriuretic peptides, iloprost, and revestrol can be studied.

Diagnosed IMA spasm is a relatively rare complication and only few reports are available in the literature. It begs for more information in order to work out adequate treatment.

\section{Conclusion}

Intraoperative IMA spasm limits its use, but adequate measures may resolve the spasm and retain the IMA as a 
preferred graft. Postoperative IMA spasm is highly lethal and unfamiliar condition, which requires prompt actions in order to avoid complications. We proposed stepwise algorithms for intra- and postoperative management that can serve as a guide, but does not call for absolute obedience, as every case still requires an individual approach.

\section{Conflict of Interest}

The authors reported no conflict of interest and no funding was received for this work.

\section{References}

[1] Tector, A.J., Schmahl, T.M. and Canino, V.R. (1983) The Internal Mammary Artery Graft: The Best Choice for Bypass of the Diseased Left Anterior Descending Coronary Artery. Circulation, 68, II214-II217.

[2] Stone, G.W. and Hartzler, G.O. (1989) Spontaneous Reversible Spasm in an Internal Mammary Artery Graft Causing Acute Myocardial Infarction. American Journal of Cardiology, 64, 822-823. http://dx.doi.org/10.1016/0002-9149(89)90777-7

[3] Lorusso, R., Crudeli, E., Lucà, F., De Cicco, G., Vizzardi, E., D’Aloia, A. and Gelsomino, S. (2012) Refractory Spasm of Coronary Arteries and Grafted Conduits after Isolated Coronary Artery Bypass Surgery. Annals of Thoracic Surgery, 93, 545-551. http://dx.doi.org/10.1016/j.athoracsur.2011.09.078

[4] Sarabu, M.R., McClung, J.A., Fass, A. and Reed, G.E. (1987) Early Postoperative Spasm in Left Internal Mammary Artery Bypass Grafts. Annals of Thoracic Surgery, 44, 199-200. http://dx.doi.org/10.1016/S0003-4975(10)62041-3

[5] Kong, B., Kopelman, H., Segal, B.L. and Iskandrian, A.S. (1988) Angiographic Demonstration of Spasm in a Left Internal Mammary Artery Used as a Bypass to the Left Anterior Descending Coronary Artery. American Journal of Cardiology, 61, 1363. http://dx.doi.org/10.1016/0002-9149(88)91191-5

[6] Mills, N.L. and Ochsner, J.L. (1975) Preparations of Internal Mammary Arteries for Coronary Bypass with Intraluminal Papaverine. Journal of Cardiovascular Surgery (Torino), 16, 632-633.

[7] Green, G.E. (1971) Rate of Blood Flow from the Internal Mammary Artery. Surgery, 70, 809-813.

[8] Battaloglu, B., Nisanoglu, V., Erdil, N., Ozgur, B., Eroglu, T., Aydin, N., Kaynak, M. and Secici, S. (2007) Effects of Pretreatment with Different Topical Vasodilators on Blood Flow in the Internal Mammary Artery: A Prospective Randomized Study. Heart Surgery Forum, 10, E136-E140. http://dx.doi.org/10.1532/HSF98.20061166

[9] Sasson, L., Cohen, A.J., Hauptman, E. and Schachner, A. (1995) Effect of Topical Vasodilators on Internal Mammary Arteries. Annals of Thoracic Surgery, 59, 494-496. http://dx.doi.org/10.1016/0003-4975(94)00896-F

[10] Nili, M., Stamler, A., Sulkes, J. and Vidne, B.A. (1999) Preparation of the Internal Thoracic Artery by Vasodilator Drugs: Is It Really Necessary? A Randomized Double-Blind Placebo-Controlled Clinical Study. European Journal Cardio-Thoracic Surgery, 16, 560-563. http://dx.doi.org/10.1016/S1010-7940(99)00308-5

[11] Formica, F., Ferro, O., Brustia, M., Corti, F., Colagrande, L., Bosisio, E. and Paolini, G. (2006) Effects of Papaverine and Glycerylnitrate-Verapamil Solution as Topical and Intraluminal Vasodilators for Internal Thoracic Artery. Annals of Thoracic Surgery, 81, 120-124. http://dx.doi.org/10.1016/j.athoracsur.2005.06.037

[12] Yildiz, O., Ciçek, S., Ay, I., Demirkiliç, U. and Tuncer, M. (1996) Hypertension Increases the Contractions to Sumatriptan in the Human Internal Mammary Artery. Annals of Thoracic Surgery, 62, 1392-1395; Discussion 1396. http://dx.doi.org/10.1016/0003-4975(96)00674-1

[13] Tanaka, N. (2009) Pharmacological Studies on Responsiveness of 5-Hydroxytryptamine in Overcoming Perioperative Spasm of Coronary Artery Bypass Graft. Yakugaku Zasshi, 129, 1049-1053. http://dx.doi.org/10.1248/yakushi.129.1049

[14] Grapow, M.T., Reineke, D.C., Kern, T., Müller-Schweinitzer, E., Carrel, T. and Eckstein, F.S. (2009) Human Internal Thoracic Arteries from Diabetic Patients Are Resistant to Endothelial Dysfunction. Fundamental \& Clinical Pharmacology, 23, 567-572. http://dx.doi.org/10.1111/j.1472-8206.2009.00707.x

[15] Turoni, C.M., de Bruno, M.P., Coviello, A., Marañón, R.O., Herrera, R.N., Muntaner, J. and Proto, V. (2007) Internal Mammary Artery Grafts Reactivity in Hypertensive Patients: Role of Stretching in Extraendothelial Nitric Oxide. Clinical and Experimental Hypertension, 29, 327-344. http://dx.doi.org/10.1080/10641960701500570

[16] He, G.W., Fan, K.Y., Chiu, S.W. and Chow, W.H. (2000) Injection of Vasodilators into Arterial Grafts through Cardiac Catheter to Relieve Spasm. Annals of Thoracic Surgery, 69, 625-628. http://dx.doi.org/10.1016/S0003-4975(99)01341-7

[17] Janelle, G.M., Urdaneta, F., Martin, T.D. and Lobato, E.B. (2000) Effects of Calcium Chloride on Grafted Internal Mammary Artery Flow after Cardiopulmonary Bypass. Journal of Cardiothoracic and Vascular Anesthesia, 14, 4-8. 
http://dx.doi.org/10.1016/S1053-0770(00)90046-6

[18] Cantürk, E., Arslan, C., Altınok, A., Özyazgan, S., Beşirli, K., Bozkurt, A.K. and Akkan, G. (2010) The in vitro Effects of Iloprost with Other Vasodilators on the Human Internal Thoracic Artery. Annals of Thoracic and Cardiovascular Surgery, 16, 78-84.

[19] Akar, F., Manavbasi, Y., Parlar, A.I., Ulus, A.T. and Katircioglu, S.F. (2007) The Gender Differences in the Relaxation to Levosimendan of Human Internal Mammary Artery. Cardiovascular Drugs and Therapy, 21, 331-338. http://dx.doi.org/10.1007/s10557-007-6047-x

[20] Deja, M.A., Gołba, K.S., Malinowski, M., Woś, S., Kolowca, M., Biernat, J., Kajor, M. and Spyt, T.J. (2005) Skeletonization of Internal Thoracic Artery Affects Its Innervation and Reactivity. European Journal of Cardio-Thoracic Surgery, 28, 551-557. http://dx.doi.org/10.1016/j.ejcts.2005.06.037

[21] Tanaka, K.A., Szlam, F., Katori, N., Tsuda, A. and Levy, J.H. (2004) In Vitro Effects of Antihypertensive Drugs on Thromboxane Agonist (U46619)-Induced Vasoconstriction in Human Internal Mammary Artery. British Journal of Anaesthesia, 93, 257-262. http://dx.doi.org/10.1093/bja/aeh189

[22] Harskamp, R.E., McNeil, J.D., van Ginkel, M.W., Bastos, R.B., Baisden, C.E. and Calhoon, J.H. (2008) Postoperative Internal Thoracic Artery Spasm after Coronary Artery Bypass Grafting. Annals of Thoracic Surgery, 85, 647-649. http://dx.doi.org/10.1016/j.athoracsur.2007.08.015

[23] Tarhan, A., Kehlibar, T., Yapici, F., Yilmaz, M., Arslan, Y., Yapici, N. and Ozler, A. (2006) Role of Physiological State 'Normothermia' in Internal Thoracic Artery Spasm after Harvesting. European Journal Cardio-Thoracic Surgery, 30, 749-752. http://dx.doi.org/10.1016/j.ejcts.2006.09.001

[24] Choi, J.B. and Lee, S.Y. (1996) Skeletonized and Pedicled Internal Thoracic Artery Grafts: Effect on Free Flow during Bypass. Annals of Thoracic Surgery, 61, 909-913. http://dx.doi.org/10.1016/0003-4975(95)01171-4

[25] Massa, G., Johansson, S., Kimblad, P.O., Sjöberg, T. and Steen, S. (1991) Might Free Arterial Grafts Fail Due to Spasm? Annals of Thoracic Surgery, 51, 94-101. http://dx.doi.org/10.1016/0003-4975(91)90458-3

[26] Tabel, Y., Hepağuşlar, H., Erdal, C., Catalyürek, H., Acikel, U., Elar, Z. and Aslan, O. (2004) Diltiazem Provides Higher Internal Mammary Artery Flow than Nitroglycerin during Coronary Artery Bypass Grafting Surgery. European Journal Cardio-Thoracic Surgery, 25, 553-559. http://dx.doi.org/10.1016/j.ejcts.2004.01.004

[27] Gaudiani, V.A., Buch, W.S., Chin, A.K., Ayres, L.J. and Fogarty, T.J. (1988) An Improved Technique for the Internal Mammary Artery Coronary Bypass Graft Procedure. Journal of Cardiac Surgery, 3, 467-473. http://dx.doi.org/10.1111/j.1540-8191.1988.tb00439.x

[28] Jeanmart, H., Perrault, L.P., Desjardins, N., Chavanon, O., Carrier, M. and Fonger, J.D. (2001) Arterial Balloon Catheter: A New Atraumatic Device for Dilating Arterial Grafts. Annals of Thoracic Surgery, 72, 810-815, Discussion 816. http://dx.doi.org/10.1016/S0003-4975(01)02895-8

[29] Abad, C., Valerón, M.E., Cáceres, J.J. and Avalos, O. (2001) Preparation of the Internal Mammary Artery with the IMAG Fogarty Balloon Catheter. Minerva cardioangiologica, 49, 263-266.

[30] Minami, T., Suzuki, S., Isomatsu, Y., Kasama, K., Matsuki, Y. and Masuda, M. (2010) Usefulness of Photo Dynamic Eye System for Detection of Graft Spasm in Off-Pump Coronary Artery Bypass Grafting. Kyobu Geka, 63, 809-812.

[31] Bertona, R., De Candia, G., Boccuzzi, G., Ribichini, F., Agostini, M. and Vassanelli, C. (2004) Left Internal Mammary Artery Graft Stenosis. Atherosclerosis, Spasm or Kinking? Italian Heart Journal. Supplement, 5, 53-58.

[32] Fakiolas, C.N., Adamopoulou, E.N., Kouvaras, G.A., Olympios, C.D. and Foussas, S.G. (1995) Systolic Segmental Disappearance of Internal Mammary Artery Graft. Correlation with Prolonged Spasm of the Graft. Acta Cardiologica, 50, 71-77.

[33] Sanders, L.H. and Newman, M.A. (2005) Intractable Postoperative Internal Thoracic Artery Spasm Managed with Angiographic Intraluminal Papaverine. Journal of Thoracic and Cardiovascular Surgery, 130, 938-940. http://dx.doi.org/10.1016/j.jtcvs.2005.04.022

[34] Kitamura, H., Nakayama, K. and Kitano, T. (2001) A Case of Refractory Spasm of Multiple Coronary Arteries and Left Internal Thoracic Artery Graft Following Off-Pump CABG. Kyobu Geka, 54, 1103-1106.

[35] Kollar, A., Simonton, C.A., Thomley, A.M. and Selle, J.G. (1996) Balloon Angioplasty of the Internal Mammary Artery Trunk for Early Postoperative Ischemia: A Case Report. Catheterization and Cardiovascular Diagnosis, 37, 49-51. http://dx.doi.org/10.1002/(SICI)1097-0304(199601)37:1<49::AID-CCD12>3.0.CO;2-R

[36] Pratt, G.F., Erickson, M., Provenzano, S., Mews, G. and Edwards, M. (2008) Intractable LIMA Spasm in the Postoperative Period Treated by Placement of 'Bridging' Stent. Annals of Thoracic Surgery, 86, 1985-1987. http://dx.doi.org/10.1016/j.athoracsur.2008.05.035

[37] Vogt, P.R., Hess, O. and Turina, M.I. (1996) Internal Mammary Artery Spasm Immediately after Grafting to the Left Anterior Descending Artery: Diagnosis and Treatment. European Heart Journal, 17, 804. 
http://dx.doi.org/10.1093/oxfordjournals.eurheartj.a014950

[38] Arnaudov, D., Cohen, A.J., Zabeeda, D., Hauptman, E., Sasson, L., Schachner, A. and Ezra, S. (1996) Effect of Systemic Vasodilators on Internal Mammary Flow during Coronary Bypass Grafting. Annals of Thoracic Surgery, 62, 1816-1819. http://dx.doi.org/10.1016/S0003-4975(96)00741-2

[39] Polvani, G., Marino, M.R., Roberto, M., Dainese, L., Parolari, A., Pompilio, G., Di Matteo, S., Fumero, A., Cannata, A., Barili, F. and Biglioli, P. (2002) Acute Effects of 17 $\beta$-Estradiol on Left Internal Mammary Graft after Coronary Artery Bypass Grafting. Annals of Thoracic Surgery, 74, 695-699. http://dx.doi.org/10.1016/S0003-4975(02)03742-6

[40] Kelsall, C.J., Chester, A.H., Amrani, M. and Singer, D.R. (2005) C-Type Natriuretic Peptide Relaxes Human Coronary Artery Bypass Grafts Preconstricted by Endothelin-1. Annals of Thoracic Surgery, 80, 1347-1351. http://dx.doi.org/10.1016/j.athoracsur.2005.01.069

[41] Buzun, L., Kleszczewski, T., Kostrzewska, A., Lisowski, P., Oleksza, P., Jackowski, R., Pedzińska, A. and Hirnle, T. (2004) Influence of Low Molecular Weight Heparin Preparations on Human Internal Thoracic Artery Contraction. European Journal of Cardio-Thoracic Surgery, 26, 951-955.

[42] Coskun, B., Soylemez, S., Parlar, A.I., Tulga Ulus, A., Fehmi Katircioglu, S. and Akar, F. (2006) Effect of Resveratrol on Nitrate Tolerance in Isolated Human Internal Mammary Artery. Journal of Cardiovascular Pharmacology, 47, 437445.

[43] Ege, T., Gur, O., Karadag, C.H. and Duran, E. (2010) Evaluation of Iloprost to Prevent Vasospasm in Coronary Artery Bypass Grafts. Journal of International Medical Research, 38, 1759-1763. http://dx.doi.org/10.1177/147323001003800521

[44] Watanabe, G., Noda, Y., Takagi, T., Tomita, S., Yamaguchi, S. and Kiuchi, R. (2013) Fasudil Is a Superior Vasodilator for the Internal Thoracic Artery in Coronary Surgery. Annals of Thoracic Surgery, 96, 543-547. http://dx.doi.org/10.1016/j.athoracsur.2013.04.039

[45] Cracowski, J.L., Chavanon, O., Durand, M., Borrel, E., Devillier, P., Mallion, J.M. and Blin, D. (1997) Effect of LowDose Positive Inotropic Drugs on Human Internal Mammary Artery Flow. Annals of Thoracic Surgery, 64, 1742-1746. http://dx.doi.org/10.1016/S0003-4975(97)01103-X

[46] Usta, C., Eksert, B., Gölbasi, I., Bigat, Z. and Ozdem, S.S. (2006) The Role of Potassium Channels in the Vasodilatory Effect of Levosimendan in Human Internal Thoracic Arteries. European Journal of Cardio-Thoracic Surgery, 30, 329332. http://dx.doi.org/10.1016/j.ejcts.2006.05.019

[47] Akar, F., Manavbasi, Y., Parlar, A.I., Ulus, A.T. and Katircioglu, S.F. (2007) The Gender Differences in the Relaxation to Levosimendan of Human Internal Mammary Artery. Cardiovascular Drugs and Therapy, 21, 331-338. http://dx.doi.org/10.1007/s10557-007-6047-x

[48] Mirkhani, H., Shafa, M. and Khazraei, H. (2009) Comparison of the Effects of Levosimendan and Papaverine on Human Internal Mammary Artery and Saphenous Vein. Cardiovascular Drugs and Therapy, 23, 355-359. http://dx.doi.org/10.1007/s10557-009-6197-0

[49] Liu, J.J., Doolan, L.A., Xie, B., Chen, J.R. and Buxton, B.F. (1997) Direct Vasodilator Effect of Milrinone, an Inotropic Drug, on Arterial Coronary Bypass Grafts. FANZCA. Journal of Thoracic and Cardiovascular Surgery, 113, 108-113. http://dx.doi.org/10.1016/S0022-5223(97)70405-7

[50] Lobato, E.B., Janelle, G.M., Urdaneta, F. and Martin, T.D. (2001) Comparison of Milrinone versus Nitroglycerin, Alone and in Combination, on Grafted Internal Mammary Artery Flow after Cardiopulmonary Bypass: Effects of $\alpha$ Adrenergic Stimulation. Journal of Cardiothoracic and Vascular Anesthesia, 15, 723-727. http://dx.doi.org/10.1053/jcan.2001.28316

[51] Mollhoff, T., Schmidt, C., Van Aken, H., et al. (2002) Myocardial Ischaemia in Patients with Impaired Left Ventricular Function Undergoing Coronary Artery Bypass Grafting-Milrinone versus Nifedipine. European Journal of Anaesthesiology, 19, 796-802.

[52] Irat, A.M., Aslamaci, S., Karasu, C. and Ari, N. (2006) Alteration of Vascular Reactivity in Diabetic Human Mammary Artery and the Effects of Thiazolidinediones. Journal of Pharmacy and Pharmacology, 58, 1647-1653.

http://dx.doi.org/10.1211/jpp.58.12.0012 